\title{
COMPATIBILIDADE DE MILHO TRANSGÊNICO COM O PARASITOIDE Trichogramma pretiosum
}

\author{
DANIEL SPAGNOL ${ }^{1}$, ANDERSON DIONEI GRÜTZMACHER ${ }^{1}$, RODOLFO VARGAS CASTILHOS ${ }^{2}$, \\ RAFAEL ANTONIO PASINI ${ }^{1}$, RONALDO ZANTEDESCHI ${ }^{1}$ e ANA PAULA SCHNEID AFONSO DA ROSA ${ }^{3}$
}

\author{
IUniversidade Federal de Pelotas (Ufpel), Pelotas, RS, Brasil-spagnol.agro@gmail.com; anderson.grutzmacher@pq.cnpq.br; \\ rafa.pasini@yahoo.com.br; ronaldozantedeschi@gmail.com \\ ${ }^{2}$ Empresa de Pesquisa Agropecuária e Extensão Rural de Santa Catarina (EPAGRI), Chapecó, SC, Brasil \\ rodolfocastilhos@epagri.sc.gov.br \\ ${ }^{3}$ Embrapa Clima Temperado, Pelotas, RS, Brasil - ana.afonso@embrapa.com.br
}

Revista Brasileira de Milho e Sorgo, v.16, n.1, p. 43-51, 2017

\begin{abstract}
RESUMO - Plantas de milho transgênicas que expressam toxinas da bactéria Bacillus thuringiensis (Bt) são uma alternativa para o controle de insetos-praga na cultura. No entanto, estas toxinas podem ser encontradas no pólen do milho, e organismos não alvo, como os inimigos naturais, podem ser prejudicados. Assim, o objetivo deste trabalho foi avaliar o efeito do pólen de três híbridos de milho transgênicos sobre parâmetros biológicos de adultos do parasitoide de ovos Trichogramma pretiosum em condições laboratoriais. Fêmeas recém-emergidas de T. pretiosum foram individualizadas em tubos de Duran contendo como alimento mel acrescido do pólen dos híbridos de milho transgênico AG 8011 YG (Cry1Ab), AS 1551 VT PRO (Cry1A. 105 + Cry 2Ab2) e Status Viptera (Vip3Aa20), e de seus respectivos isogênicos convencionais. Diariamente, foram ofertados, em cada tubo, ovos de Anagasta kuehniella para parasitismo. Os parâmetros avaliados foram: longevidade das fêmeas expostas ao pólen, taxa de parasitismo total, taxa de emergência e razão sexual da progênie. Os híbridos transgênicos: AG 8011 YG (Cry1Ab), AS 1551 VT PRO (Cry1A. 105 + Cry 2Ab2) e Status Viptera (Vip3Aa20), bem como seus isogênicos convencionais, não causaram efeitos deletérios sobre a longevidade e capacidade de parasitismo das fêmeas de T. pretiosum expostas aos respectivos pólens. A emergência e razão sexual da progênie também não foram negativamente afetadas, possibilitando assim a compatibilização dos transgênicos avaliados com o controle biológico natural e aplicado exercido por este parasitoide. Palavras-chave: Bacillus thuringiensis, transgenia, manejo integrado de pragas, controle biológico, Zea mays.
\end{abstract}

\section{COMPATIBILITY OF TRANSGENIC CORN WITH THE PARASITOID Trichogramma pretiosum}

\begin{abstract}
Transgenic corn expressing Bacillus thuringiensis (Bt) toxins is an alternative for pest control in corn fields. However, some non-target organisms such as natural enemies can be impaired by corn pollen containing toxins. Therefore, the aim of this work was to evaluate the effect of the pollen from three transgenic corn varieties on biological parameters of the egg parasitoid Trichogramma pretiosum under laboratorial conditions. Emerged females of $T$. pretiosum were placed into Duran tubes and fed with honey + pollen of corn hybrids AG 8011 YG (Cry1Ab), AS 1551 VT PRO (Cry1A. 105 + Cry 2Ab2) and Status Viptera (Vip3Aa20), as well as their respective isogenic. Daily, eggs of Anagasta kuehniella were offered in each tube for parasitism. The parameters evaluated were longevity of females exposed to pollen, total parasitism, progeny emergency and sex ratio. The transgenic hybrids AG 8011 YG (CrylAb), AS 1551 VT PRO (Cry1A. 105 + Cry 2Ab2), Status Viptera (Vip3Aa20) and their isogenic showed no deleterious effect on longevity and parasitism capacity of T. pretiosum females exposed to respective pollen. Emergency and sex ratio from progeny were also not adversely affected, thus enabling the compatibility of the evaluated transgenic with biological control by this parasitoid.
\end{abstract}

Keywords: Bacillus thuringiensis, transgenes, integrated pest management, biological control, Zea mays. 
Uma das estratégias de supressão populacional e controle de insetos mastigadores na cultura do milho se baseia na utilização de plantas geneticamente modificadas pela introdução de genes de $\mathrm{Ba}$ cillus thuringiensis (Berliner, 1911) (Bacillaceae), os quais levam à produção de proteínas tóxicas aos insetos.

Dado que as toxinas presentes no milho Bt são expressas também no pólen da planta, organismos não alvo, como polinizadores e inimigos naturais, são expostos de forma direta ou indireta à toxina, o que pode prejudicar suas populações na lavoura (Sisterson et al., 2007). Entre os inimigos naturais de insetos -praga do milho, destacam-se os parasitoides de ovos do gênero Trichogramma (Foresti et al., 2012), os quais podem parasitar lepidópteros-praga. Estes parasitoides obtêm nutrientes a partir do néctar e pólen de plantas, que lhes garantem uma vantajosa longevidade, fecundidade, propensão de voo e capacidade de parasitismo (Zhang et al., 2004; Begum et al., 2006). Nesse sentido, a entomofauna benéfica, sobretudo Trichogramma spp, pode ser afetada negativamente em lavouras de milho Bt.

Dentro do gênero Trichogramma, a espécie Trichogramma pretiosum (Riley, 1879) (Hymenoptera: Trichogrammatidae) é uma das mais estudadas e utilizadas em programas de controle biológico no Brasil (Parra \& Zucchi, 1997). Um exemplo da importância de T. pretiosum é descrito por Nava e Nachtigal (2010), os quais relataram que somente no ano de 2008 foram realizadas liberações de $T$. pretiosum em aproximadamente 3.000 hectares de lavouras comerciais de milho no município de Santa Maria-RS, para o controle de Spodoptera frugiperda.

Com o aumento da utilização do milho Bt, o possível impacto negativo desta tecnologia sobre espécies não alvo se tornou uma preocupação por parte de agricultores e consumidores e, consequentemente, alvo de estudo da comunidade científica (Dabrowski, 2007). Assim, testes que avaliem a compatibilidade da transgenia com o controle biológico, dentro do manejo integrado de pragas (MIP), são importantes para obtenção de informações que venham a auxiliar na preservação de inimigos naturais nas lavouras de milho.

Alguns autores relatam a ausência de efeito adverso do pólen de plantas transgênicas (Bt) para Trichogrammatideos. A espécie Trichogramma chilonis (Ishii,1941) (Hymenoptera: Trichogrammatidae) não foi afetada adversamente pelo pólen de algodão Bt em testes laboratoriais (Geng et al., 2006). $\mathrm{Na}$ cultura do milho, as espécies Trichogramma brassicae (Bezdenko, 1968) (Hymenoptera: Trichogrammatidae) e Trichogramma ostriniae (Pang \& Chen, 1974) (Hymenoptera: Trichogrammatidae) não apresentaram susceptibilidade a toxinas $\mathrm{Bt}$, uma vez que não tiveram nenhum parâmetro biológico impactado negativamente quando alimentados com pólen de milho transgênico (Zhang et al., 2004; Wang et al., 2007).

O parasitoide $T$. pretiosum, por estar associado à cultura do milho como importante inimigo natural de lepidópteros-praga, se constitui em um importante bioindicador do impacto da tecnologia Bt sobre organismos não alvo (Figueiredo et al., 2015). No entanto, informações acerca do efeito de certas proteínas $\mathrm{Bt}$ sobre a referida espécie são escassas, o que torna necessária a avaliação do impacto de diferentes toxinas sobre este parasitoide.

Desta forma, objetivou-se avaliar o efeito do pólen de três híbridos de milho transgênico, expressando as proteínas Bt Cry 1Ab, Cry1A. $105+$ Cry 2Ab2 e Vip3Aa20, sobre parâmetros biológicos de adultos do parasitoide de ovos T. pretiosum. 


\section{Material e Métodos}

Para realização do bioensaio foram cultivados em casa de vegetação climatizada os híbridos de milho Bt AG 8011 YG (Cry 1Ab), AS 1551 VT PRO (Cry1A. 105 + Cry 2Ab2) e Status Viptera (Vip3Aa20), assim como seus respectivos isogênicos (não $\mathrm{Bt}$ ). As plantas foram cultivadas em vasos plásticos $(20 \mathrm{~cm}$ diâmetro inferior x $24 \mathrm{~cm}$ diâmetro superior x $22 \mathrm{~cm}$ altura), dispostos sobre pratos plásticos que serviram como reservatório de água. Cada vaso continha em média $12 \mathrm{Kg}$ de solo do tipo planossolo (hidromórfico), o qual foi adubado com NPK (5-20-20) (Reunião Técnica Anual do Milho, 2013). Em cada vaso foram semeadas quatro sementes, e o desbaste foi realizado no estádio fenológico V2, permanecendo duas plantas por vaso.

Os parasitoides utilizados no bioensaio foram obtidos de criação mantida em laboratório sobre ovos do hospedeiro alternativo Anagasta kuehniella (Zeller, 1879) (Lepidoptera: Pyralidae) (Parra et al., 2014).

A coleta do pólen se deu diretamente das plantas, amarrando-se sacos de papel sobre o pendão por seis a sete dias. Posteriormente, o pólen coletado foi seco ao ar por 24 horas e peneirado em malha de 200 $\mu \mathrm{m}$ para retirada de anteras e outros contaminantes.

O bioensaio foi conduzido em sala com condições controladas de temperatura $\left(25 \pm 1^{\circ} \mathrm{C}\right)$, umidade relativa $(70 \pm 10 \%)$ e fotofase (14 horas), e consistiu na exposição de fêmeas de $T$. pretiosum ao pólen dos três híbridos Bt e de seus respectivos isogênicos, além de um tratamento testemunha, totalizando sete tratamentos. O pólen de cada híbrido foi misturado com mel, na proporção de $20 \mathrm{mg} / \mathrm{mL}$. No tratamento testemunha foi ofertado somente mel. Para cada tratamento foram utilizadas 20 fêmeas recém-emergidas do parasitoide, as quais foram individualizadas em tubos de Duran. A oferta dos tratamentos se deu em forma de gotículas depositadas em tira de papel Parafilm, sendo estas renovadas diariamente.

A cada 24 horas foi oferecido para cada fêmea uma cartela de papel cartolina azul celeste $(2,5 \times 0,5$ $\mathrm{cm}$ ), contendo 40 ovos do hospedeiro alternativo $A$. kuehniella colados com goma arábica a $10 \%$ e previamente inviabilizados em lâmpada germicida por uma hora. Os tubos foram lacrados com filme plástico de PVC para evitar a fuga dos parasitoides e furados com alfinete entomológico número zero para possibilitar a aeração. As cartelas contendo os ovos expostos aos parasitoides em cada dia foram retiradas e armazenadas nas mesmas condições do bioensaio para posterior emergência da progênie (F1).

As fêmeas ficaram expostas aos tratamentos por aproximadamente 15 dias, e os parâmetros avaliados foram: longevidade das fêmeas expostas ao pólen; número diário e acumulado de ovos parasitados pelas fêmeas expostas ao pólen; taxa de emergência e razão sexual da progênie.

O delineamento experimental utilizado foi inteiramente casualizado, com 20 repetições para cada tratamento, sendo cada fêmea individualizada no tubo e exposta ao pólen considerada uma repetição. Os dados foram testados quanto à normalidade pelo teste de Shapiro-Wilk, e quanto à homogeneidade das variâncias pelo teste de Barlett. Os dados de emergência, razão sexual e parasitismo total foram submetidos à análise de variância. Previamente, os dados de parasitismo total foram transformados em $\sqrt{ }(\mathrm{x})$ para atender o pressuposto de normalidade. Para as variáveis em que o teste $\mathrm{F}$ da análise de variância evidenciou diferença significativa, foi realizada a comparação de médias pelo teste de Tukey a 5\% de probabilidade. Os dados de longevidade não puderam 
ser normalizados, e foram submetidos à análise de variância não paramétrica de Kruskal-Wallis. Todas as análises foram realizadas utilizando-se o software estatístico Assistat 7.7 (Silva \& Azevedo, 2016).

\section{Resultados e Discussão}

O pólen dos híbridos $\mathrm{Bt}$ e não $\mathrm{Bt}$ não afetou a longevidade das fêmeas de $T$. pretiosum $(\mathrm{H}=12,22$; $\mathrm{gl}=6 ; \mathrm{p}=0,06$ ), com valores observados entre $14,80 \mathrm{e}$ 15,33 dias (Tabela 1). Da mesma forma, a capacidade de parasitismo diário em ovos de A. kuehniella não foi prejudicada mediante o fornecimento de dieta com mel acrescido do pólen dos diferentes híbridos, sendo semelhante à verificada na testemunha. O parasitismo em todos os tratamentos no primeiro dia foi de 20 a 23 ovos, com um decréscimo gradual a partir do segundo dia (Figura 1). O parasitismo total por fêmea não foi afetado (Tabela 1) e variou de 74,82 ovos em fêmeas alimentadas com mel + pólen do híbrido Bt Status
Viptera a 79,90 ovos em fêmeas alimentadas somente com mel (testemunha) $(\mathrm{F}=1,03 ; \mathrm{gl}=6 ; \mathrm{p}=0,40)$.

A taxa de emergência da progênie foi satisfatória em todos os tratamentos, com níveis superiores a 95\%. Para este parâmetro, o híbrido Bt AS 1551 VT PRO (Cry1A. 105 + Cry 2Ab2) apresentou valores superiores aos do seu isogênico AS 1551 e do híbrido Bt Status Viptera (VIP3Aa20) $(\mathrm{F}=5,20 ; \mathrm{gl}=6$; $\mathrm{p}=0,001$ ) (Tabela 1). No entanto, a taxa de emergência de todos os tratamentos se mostrou semelhante à obtida na testemunha, não evidenciando efeito nocivo sobre a emergência da progênie. No que diz respeito à razão sexual da progênie, os valores obtidos não diferiram entre os tratamentos $(\mathrm{F}=0,51 ; \mathrm{gl}=6 ; \mathrm{p}=0,79)$, com índices variando de 0,70 a 0,73 (Tabela 1 ).

Em lavouras de milho, parasitoides do gênero Trichogramma entram facilmente em contato com o pólen das plantas. De acordo com Zhang et al. (2004), fêmeas de $T$. brassicae alimentadas com pólen de milho e água, tiveram incremento na longevidade

Tabela 1. Efeito do pólen de híbridos de milho transgênico e seus isogênicos convencionais sobre parâmetros biológicos de Trichogramma pretiosum. Pelotas-RS, 2012.

\begin{tabular}{|c|c|c|c|c|c|}
\hline Tratamento & $\begin{array}{l}\text { Proteína } \\
\text { expressa }\end{array}$ & $\begin{array}{l}\text { Longevidade } \\
\text { (Dias) }^{*}\end{array}$ & $\begin{array}{c}\text { Parasitismo } \\
\text { total } \\
2^{* *}\end{array}$ & $\begin{array}{c}\text { Emergência } \\
(\%)^{1}\end{array}$ & $\begin{array}{c}\text { Razão } \\
\text { sexual }^{* *}\end{array}$ \\
\hline Testemunha & - & $14,80 \pm 0,20^{\mathrm{ns}}$ & $79,90 \pm 2,75^{\text {ns }}$ & $97,30 \pm 0,10 \mathrm{ab}$ & $0,72 \pm 0,02^{\mathrm{ns}}$ \\
\hline AG 8011 YG & Cry1Ab & $15,13 \pm 0,20$ & $79,21 \pm 1,29$ & $97,12 \pm 0,30 \mathrm{ab}$ & $0,70 \pm 0,02$ \\
\hline AG 8011 & - & $14,80 \pm 0,24$ & $76,72 \pm 1,83$ & $96,97 \pm 0,44 \mathrm{ab}$ & $0,73 \pm 0,02$ \\
\hline AS 1551 VT PRO & $\begin{array}{l}\text { Cry } 1 \text { A. } 105 \\
+ \text { Cry 2Ab2 }\end{array}$ & $15,13 \pm 0,09$ & $76,60 \pm 1,30$ & $98,20 \pm 0,11 \mathrm{a}$ & $0,70 \pm 0,01$ \\
\hline AS 1551 & - & $15,33 \pm 0,12$ & $74,90 \pm 2,12$ & $96,65 \pm 0,40 \mathrm{~b}$ & $0,73 \pm 0,02$ \\
\hline Status Viptera & Vip3Aa20 & $14,93 \pm 0,06$ & $74,82 \pm 1,25$ & $96,00 \pm 0,43 b$ & $0,71 \pm 0,02$ \\
\hline Status & - & $15,14 \pm 0,09$ & $76,41 \pm 1,94$ & $97,15 \pm 0,40 \mathrm{ab}$ & $0,70 \pm 0,02$ \\
\hline
\end{tabular}

${ }^{1}$ Médias \pm E.P. seguidas pela mesma letra minúscula na coluna não diferem entre si, pelo teste (Tukey), ao nível de 5\% de probabilidade; ${ }^{2}$ Média do parasitismo acumulado por fêmea;

*ns: não significativo por Kruskal-Wallis ( $\mathrm{p}>0,05)$;

**ns: não significativo pelo teste $\mathrm{F}(\mathrm{p}>0,05)$. 
AG 8011 YG

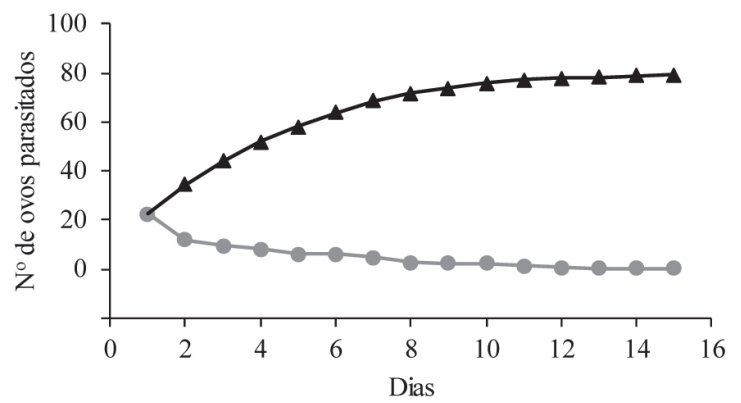

- - Parasitismo Diário $\rightarrow$-Parasitismo Acumulado

AS 1551 VT PRO

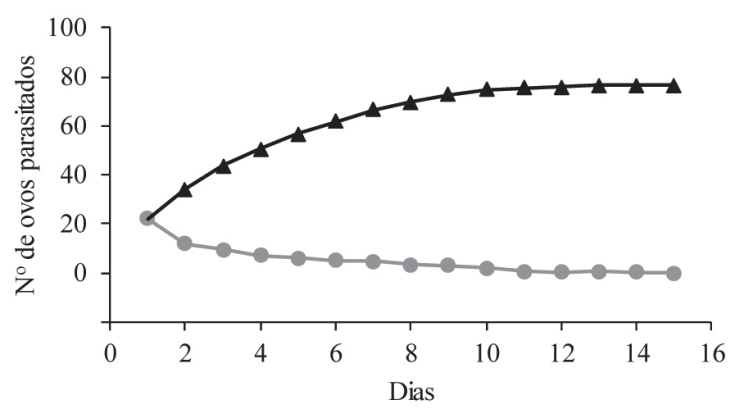

$\multimap$ Parasitismo Diário $\multimap$-Parasitismo Acumulado

\section{Status Viptera}

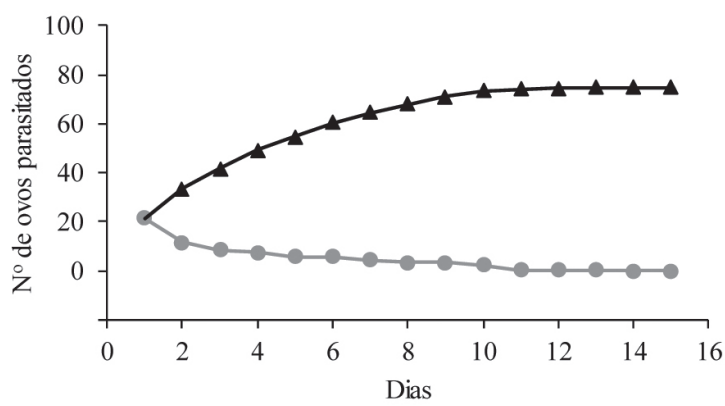

$\rightarrow$ Parasitismo Diário $\rightarrow$ Parasitismo Acumulado

Testemunha

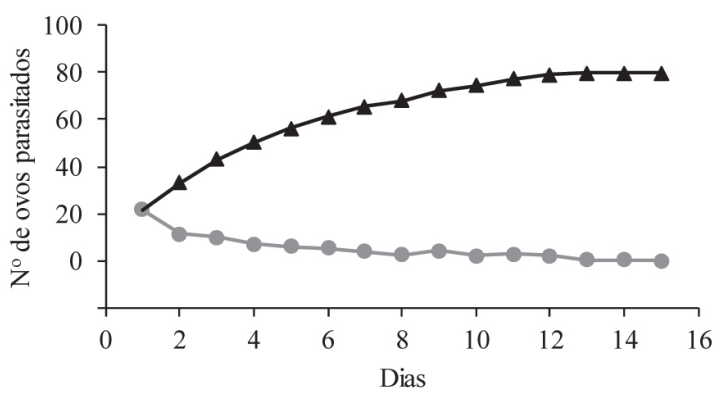

$\multimap$ Parasitismo Diário $\rightarrow$ Parasitismo Acumulado
AG 8011

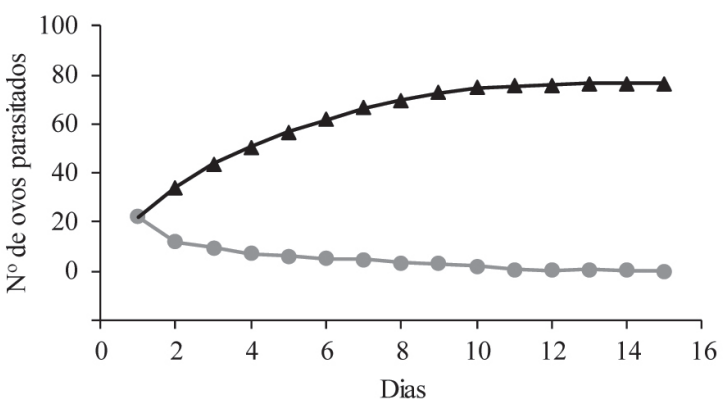

$\rightarrow$ - Parasitismo Diário $\rightarrow$-Parasitismo Acumulado

AS 1551

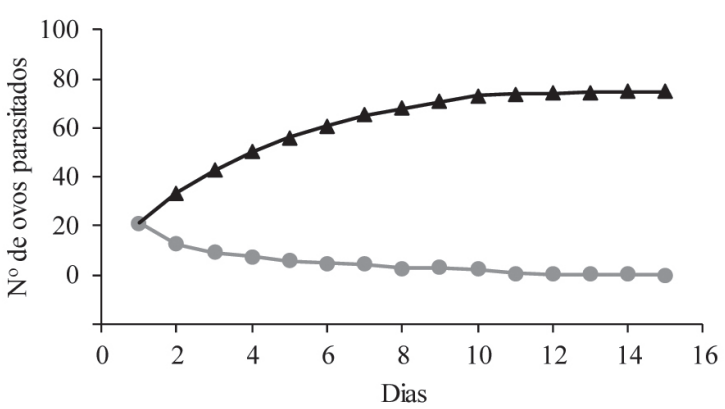

$\multimap$ Parasitismo Diário — $\leftarrow$ Parasitismo Acumulado

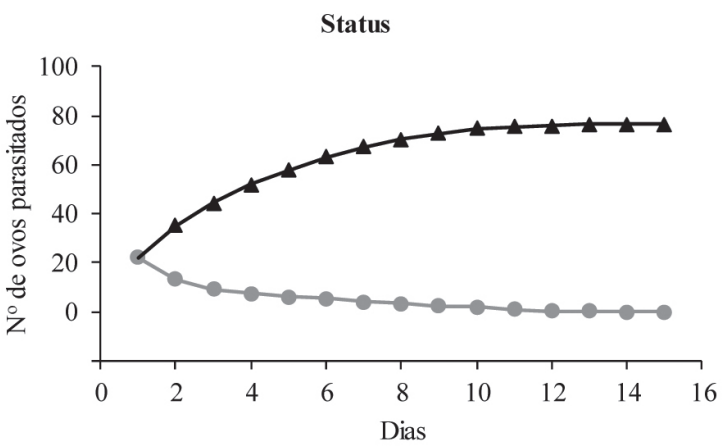

$\multimap$ Parasitismo Diário $\multimap$ Parasitismo Acumulado 
e fecundidade, demonstrando a importância desse componente para a nutrição de Trichogrammatideos. A inocuidade do pólen de milho Bt sobre organismos não alvo, mais especificamente para himenópteros polinizadores, é relatada por Hanley et al. (2003), que examinaram os efeitos de pólen de milho Bt expressando as proteínas Cry1Ab e Cry1F em larvas de abelha com quatro a cinco dias de idade e não observaram efeitos adversos na sobrevivência de larvas e pupas, bem como no peso delas e na emergência de adultos. Para adultos de abelhas, o pólen de milho Bt e a proteína purificada (Cry1Ab), nas concentrações de $0,1 \%$ e $1 \%$ (p.v), não apresentaram efeito sobre a sobrevivência dos indivíduos após serem ofertados para alimentação durante 10 dias (Babendreier et al., 2005), evidenciando o baixo impacto sobre insetos benéficos, principalmente da ordem Hymenoptera.

As proteínas expressas no pólen dos milhos transgênicos avaliados não interferem no controle biológico exercido por $T$. pretiosum, visto que não foi observada diferença no parasitismo total das fêmeas entre o pólen dos híbridos transgênicos e convencionais quando estes foram ofertados como alimento ao parasitoide (Tabela 1). Estes resultados se assemelham aos obtidos por Wang et al. (2007), os quais verificaram que o parasitismo de ovos de Ostrinia furnacalis (Guenée, 1854) (Lepidoptera: Crambidae) por $T$. ostriniae não foi prejudicado quando o parasitoide foi alimentado com suspensão de mel e pólen oriundo de milho Bt. Da mesma forma, Geng et al. (2006) também constataram que T. chilonis alimentados com pólen proveniente de algodão Bt não apresentaram redução da capacidade de parasitismo, longevidade e razão sexual, bem como na longevidade de seus descendentes.

A queda gradual do parasitismo verificado para T. pretiosum (Figura 1) é considerada uma caracterís- tica normal dessa espécie, pois parasitoides do gênero Trichogramma concentram suas posturas nos primeiros três dias após emergência (Pratissoli et al., 2006).

A longevidade e taxa de parasitismo de adultos de Trichogramma pratissolii Querino \& Zucchi, 2003 (Hymenoptera: Trichogrammatidae) e T. pretiosum alimentados com diferentes isolados Bt não foi afetada, mostrando que estas duas espécies de parasitoide e o entomopatógeno $B$. thuringiensis podem ser usados conjuntamente no MIP (Polanczyk et al., 2006). Diferentemente, a espécie $T$. pratissolii teve a emergência de sua progênie afetada quando adultos foram alimentados com isolados específicos de B. thuringiensis, sendo recomendado um aumento no número de liberações massais do parasitoide para se alcançar resultados satisfatórios de parasitismo em programas de controle biológico onde os isolados e a espécie de parasitoide em questão são utilizados (Pratissoli et al., 2006).

Adultos de Trichogramma evanescens Westwood, 1833 (Hymenoptera: Trichogrammatidae) alimentados durante cinco dias com uma solução de mel contendo $500 \mu \mathrm{g}$ de $B$. thuringiensis var. galleriae HD-129 não tiveram a longevidade de adultos e capacidade de parasitismo de ovos de Spodoptera littoralis (Boisduva, 1831) (Lepidoptera: Noctuidae) e A. kuehniella afetados negativamente (Salama \& Zak, 1985). Wang et al. (2007) também observaram taxa de emergência superior a 90\%, na progênie de T. ostriniae quando fêmeas da espécie foram alimentadas com substrato contendo pólen oriundo de milho Bt, o que evidencia a tolerância de diferentes espécies do gênero Trichogramma a $B$. thuringienesis.

As razões sexuais verificadas (Tabela 1) para $T$. pretiosum exposto ao pólen dos três híbridos de mitho $\mathrm{Bt}$ foram consideradas adequadas para programas de controle biológico, uma vez que foram superio- 
res à taxa mínima satisfatória, que é de 0,5 (Navarro, 1998).

Os cristais proteicos presentes nos três híbridos de milho $\mathrm{Bt}$ avaliados possuem especificidade para lepidópteros (Frankenhuyzen, 2009; Yu et al., 2011). A ordem Hymenoptera, que engloba insetos benéficos como parasitoides e polinizadores, tende a não apresentar susceptibilidade a toxinas de $B$. thuringiensis, e o controle biológico exercido por T. pretiosum não é prejudicado em lavouras de milho $\mathrm{Bt}$, visto que os resultados obtidos com os híbridos transgênicos foram equivalentes ou superiores aos obtidos com os respectivos híbridos convencionais.

Cultivares de milho Bt, de uma maneira geral, não apresentam efeitos nocivos diretos sobre organismos não alvo (Yaqoob et al., 2016), e a adoção desta tecnologia pode levar a consideráveis reduções no uso de inseticidas, o que contribui para o MIP em áreas de cultivo de milho onde o controle biológico se faz presente (Romeis et al., 2006).

\section{Conclusões}

O pólen das cultivares de milho híbrido $\mathrm{Bt} A \mathrm{AG}$ 8011 YG (Cry1Ab), AS 1551 VT PRO (Cry1A. $105+$ Cry 2Ab2) e Status Viptera (VIP3Aa20) não causam efeitos adversos na longevidade, no parasitismo, na emergência e razão sexual do parasitoide de ovos $T$. pretiosum, o que possibilita a integração do controle biológico exercido por este parasitoide com a transgenia em programas de manejo integrado de pragas.

\section{Agradecimentos}

Ao Conselho Nacional de Desenvolvimento Científico e Tecnológico (CNPq) pelo financiamento da pesquisa, à Embrapa Clima Temperado pelo apoio logístico.

\section{Referências}

BABENDREIER, D.; KALBERER, N. M.; ROMEIS, J.; FLURI, P.; MULLIGAN, E.; BIGLER, F. Influence of $B t$ transgenic pollen, $B t$-toxin and protease inhibitor (SBTI) ingestion on development of the hypopharyngeal glands in honeybees. Apidologie, Versailles, v. 36, n. 4, p. 585-594, 2005.

DOI: 10.1051/apido:2005049.

BEGUM, M.; GURR, G. M.; HEDBERG, P.; NICOL, H. I.; WRATTEN, S. D. Using selective food plants to maximize biological control of vineyard pests. Journal of Applied Ecology, Orange, v. 43, n. 3, p. 547-554, 2006. DOI: $10.1111 / j .1365-2664.2006 .01168 . x$.

DABROWSKI, Z. T. Evaluation of opinions on ecological consequences of growing genetically modified (GM) crops: case studies on the effects of Bt maize cultivars on nontarget organisms. Postepy Nauk Rolniczich, Warszawa, v. 59, n. 2, p. 57-70, 2007.

FIGUEIREDO, M. L. C.; CRUZ, I.; SILVA, R. B. S.; FOSTER, J. E. Biological control with Trichogramma pretiosum increases organic maize productivity by $19.4 \%$. Agronomy for Sustainable Development, Paris, v. 35, n. 3, p. 1175-1183, 2015.

DOI: $10.1007 / \mathrm{s} 13593-015-0312-3$.

FORESTI, J.; GARCIA, M. S.; BERNARDI, O.; ZART, M.; NUNES, A. M. Biologia, seleção e avaliação de linhagens de Trichogramma spp. para o controle da lagartada-espiga em milho semente. EntomoBrasilis, Vassouras, v. 5, n. 1, p. 43-48, 2012.

FRANKENHUYZEN, K. V. Insecticidal activity of Bacillus thuringiensis crystal proteins. Journal of Invertebrate Pathology, Urbana, v. 101, n. 1, p. 1-16, 2009. DOI: 10.1016/j.jip.2009.02.009.

GENG, J. H.; SHEN Z. R.; SONG K.; ZHENG L. Effect of pollen of regular cotton and transgenic BtCpTI cotton on the survival and reproduction of the parasitoid wasp Trichogramma chilonis (Hymenoptera: Trichogrammatidae) in the laboratory. Environmental 
Entomology, College Park, v. 35, n. 6, p. 1661-1668, 2006. DOI: 10.1093/ee/35.6.1661.

HANLEY, A. V.; HUANG, Z. Y.; PETT, W. L. Effects of dietary transgenic Bt corn pollen on larvae of Apis mellifera and Galleria mellonella. Journal of Apicultural Research, London, v. 42, n. 4, p. 77-81, 2003.

DOI: $10.1080 / 00218839.2003 .11101097$.

NAVA, D. E.; NACHTIGAL, G. F. Controle biológico no Sul do Brasil. Revista Brasileira de Controle Biológico, Piracicaba, v. 1, n. 1, p. 15-18, 2010.

NAVARRO, M. A. Trichogramma spp. Producción, uso y manejo em Colômbia. Guadalajara de Buga: Impretec, $1998.176 \mathrm{p}$.

PARRA, J. R. P.; ZUCCHI, R. A. Trichogramma e o controle biológico aplicado. Piracicaba: Fealq, 1997.324p.

PARRA, J. R. P.; COELHO JÚNIOR, A.; GEREMIAS, L. D.; BERTIN, A.; RAMOS, C. J. Criação de Anagasta kuehniella em pequena escala para produção de Trichogramma. Piracicaba: Occasio, 2014. 32 p.

POLANCZYK, R. A.; PRATISSOLI, D.; VIANNA, U. R.; OLIVEIRA, R. G. dos S.; ANDRADE, G. S. Interação entre inimigos naturais: Trichogramma e Bacillus thuringiensis no controle biológico de pragas agrícolas. Acta Scientiarum Agronomy, Maringá, v. 28, n. 2, p. 233-239, 2006.

DOI: $10.4025 /$ actasciagron.v28i2.1101.

PRATISSOLI, D.; POLANCZYK, R. A.; VIANNA, U. R.; ANDRADE, G. S.; OLIVEIRA, R. G. S. Desempenho de Trichogramma pratissolii Querino \& Zucchi (Hymenoptera, Trichogrammatidae) em ovos de Anagasta kuehniella (Zeller) (Lepidoptera, Pyralidae) sob efeito de Bacillus thuringiensis Berliner. Ciência Rural, Santa Maria, v. 36, n. 2, p. 369-377, 2006.

DOI: $10.1590 / \mathrm{S} 0103-84782006000200003$.

REUNIÃO TÉCNICA ANUAL DO MILHO, 58., REUNIÃO TÉCNICA ANUAL DO SORGO, 41., 2013, Pelotas. Indicações técnicas para o cultivo de milho e de sorgo no Rio Grande do Sul safras 2013/2014 e 2014/2015. Brasília, DF: Embrapa, 2013. 124 p.

ROMEIS, J.; MEISSLE, M.; BIGLER, F. Transgenic crops expressing Bacillus thuringiensis toxins and biological control. Nature Biotechnology, Londres, v. 24, n. 1, p. 6371, 2006. DOI: 10.1038/nbt1180.

SALAMA, H. S.; ZAK, I. F. N. Biological effects of Bacillus thuringiensis on the egg parasitoid, Trichogramma evanescens. Insect Science and its Application, Nairobi, v. 6, n. 2 , p. $145-148,1985$.

SILVA, F. A. S.; AZEVEDO, C. A. V. The assistant software version 7.7 and its use in the analysis of experimental data. African Journal of Agricultural Research, Nigeria, v. 11, n. 39, p. 3733-3740, 2016.

DOI: 10.5897/AJAR2016.11522.

SISTERSON, M. S.; CARRIERE, Y.; DENNEHY, T. J.; TABASHNIK, B. E. Nontarget effects of transgenic insecticidal crops: implications of source-sink population dynamics. Environmental Entomology, Annapolis, v. 36, n. 1, p. 121-127, 2007.

YU, X.; ZHEN, A.; ZHU, J.; WANG, S.; WANG, L.; DENG, Q.; LI, S.; LIU, H.; LI, P. Characterization of vegetative insecticidal protein vip genes of Bacillus thuringiensis from Sichuan Basin in China. Current Microbiology, Braunschweig, v. 62, n. 3, p. 752-757, 2011.

DOI: $10.1007 / \mathrm{s} 00284-010-9782-3$.

WANG, Z. Y.; WU, Y.; HE, K. L.; BAI, B. X. Effects of transgenic $B t$ maize pollen on longevity and fecundity of Trichogramma ostriniae in laboratory conditions. Bulletin of Insectology, Bologna, v. 60, n. 1, p. 49-55, 2007.

MACHADO, A.; CONCEIÇÃO, A. R. WinStat: sistema de análise estatístico para Windows: versão 2.0. Pelotas: UFPel, 2002.

YAQOOB, A.; SHAHID, A. A.; SAMIULLAH, T. R.; RAO, A. Q.; KHAN, M. A. U.; TAHIR, S.; MIRZA, S. A.; HUSNAIN, T. Risk assessment of Bt crops on the nontarget 
plant-associated insects and soil organisms. Journal of the Science of Food and Agriculture, Londres, v. 96, n. 8, p. 2613-2619, 2016. DOI: 10.1002/jsfa.7661.

ZHANG, G. R.; ZIMMERMANN, O.; HASSAN, S. A. Pollen as a source of food for egg parasitoids of the genus Trichogramma (Hymenoptera: Trichogrammatidae). Biocontrol Science Technology, Oxford, v. 14, n. 2, p. 201-209, 2004. DOI: 10.1080/09583150310001655648. 